\title{
Protein levels in enteral feeds: do these meet requirements in children with severe cerebral palsy?
}

\author{
Niikee Schoendorfer ${ }^{1 *}$, Ujang Tinggi ${ }^{2}$, Nita Sharp ${ }^{1}$, Roslyn Boyd ${ }^{3}$, Luis Vitetta ${ }^{4}$ and Peter S. W. Davies ${ }^{1}$ \\ ${ }^{1}$ Children's Nutrition Research Centre, The University of Queensland, School of Medicine, Herston, QLD 4029, Australia \\ ${ }^{2}$ Centre for Public Health Sciences, Queensland Health Forensic and Scientific Services, Coopers Plains, QLD 4108, Australia \\ ${ }^{3}$ Queensland Cerebral Palsy and Rehabilitation Research Centre, The University of Queensland, School of Medicine, Herston, \\ QLD 4029, Australia \\ ${ }^{4}$ Centre for Clinical and Molecular Medicine, The University of Queensland, School of Medicine, Woolloongabba, QLD 4102, \\ Australia
}

(Submitted 20 January 2011 - Final revision received 13 July 2011 - Accepted 13 July 2011 - First published online 4 November 2011)

\begin{abstract}
Children with cerebral palsy (CP) have been documented to have feeding difficulties, which increase in line with condition severity and result in lowered growth potential. Much nutrition literature surrounds energy intake and expenditure in these children, with less information available on other parameters such as protein and micronutrients, which are also important for growth and development. We examined differences in protein intake and a variety of protein metabolism indices in children with CP compared with controls. A total of twenty-four children aged 4-12 years with marked CP fed orally (O, $n$ 15) or enterally (E, $n$ 9) were recruited, including age-matched typically developing children (C, $n$ 24). Fasting blood samples were analysed for levels of albumin, creatinine, urea and urate. Parents collected an exact food replica for three consecutive days of their child's actual intake, which were directly analysed for protein content. Significant differences were found in protein intakes between the groups (mean percentage minimum requirements: $\mathrm{E}=178$ (SD 47 ); $\mathrm{O}=208$ (sD 95); $\mathrm{C}=311$ (SD 119), $P=0 \cdot 005$ ). Despite all children consuming over recommended levels, children with CP had significantly reduced levels of the protein metabolic indices compared with controls. These include as $z$-scores: albumin mean $\mathrm{C}=0.71$ (SD 1.04$)$ and $\mathrm{CP}=-0.17(\mathrm{SD} 1.60), P=0.03$; creatinine $\mathrm{C}=-2.06(\mathrm{SD} 0.46)$ and $\mathrm{CP}=-3.11$ (SD 0.98), $P<0.001 ;$ urate $\mathrm{C}=0.18(\mathrm{SD} 0.62)$ and $\mathrm{CP}=-0.58$ (SD 0.93), $P=0.002$. Post hoc analysis, the present data show potentially greater protein metabolism issues in enterally fed children, compared with the other groups. This may also support recent literature that suggests shortfalls in current recommendations.
\end{abstract}

Key words: Cerebral palsy: Enteral feeding: Protein requirements

Malnutrition is considered a typical feature of cerebral palsy (CP) as its incidence has been documented in 46-90\% of these children ${ }^{(1)}$, with occurrence generally increasing in line with severity ${ }^{(2)}$. This is believed to relate to the commonly encountered feeding difficulties caused by a variety of factors including dysphagia, gastro-oesophageal reflux, problems with oral motor control and self-feeding ability ${ }^{(3)}$.

Impaired growth is another well-documented feature of $\mathrm{CP}^{(4)}$. Much literature surrounds the relationship between malnutrition and growth with other health outcomes such as changes in healthcare requirements and participation in society $^{(5)}$ as well as bone health ${ }^{(6,7)}$ and immunological challenges $^{(3)}$ in these children.

Percutaneous gastrostomy feeding is thought to assist children to correct growth impairments due to malnutrition ${ }^{(8)}$. Many studies ${ }^{(9-15)}$ have found improvements with enteral feeding, notably in weight $z$-scores, although minimal changes have been noted for height $z$-scores. Improvements in height $z$-scores have however been documented in eight out of thirty-five children in one study ${ }^{(16)}$, although this was much less frequent than improvements in weight $z$-scores (twentyfour out of thirty-five) in the same children.

Many aspects of human physiology are interrelated. Sufficient macronutrients such as carbohydrates, fat and protein, as well as adequate micronutrients such as vitamins, minerals and trace elements, are all needed for the body to function in an integrated manner. Insufficiencies or imbalances in any of these components cause disturbances in this delicate balance ${ }^{(17)}$

Protein is important for growth, immune function and recovery from disease, as well as skeletal respiratory muscle function, which all become severely impaired when levels are low. Taking this into consideration, we decided to investigate

Abbreviation: CP, cerebral palsy.

*Corresponding author: N. Schoendorfer, fax +61 733464684, email n.schoendorfer@uq.edu.au 
actual protein consumption and a variety of other markers, which may relate to protein status in children with marked CP either orally or enterally fed and compare with controls. Other parameters considered include height, weight and BMI, plasma albumin, creatinine, urea and urate, as well as C-reactive protein as a marker of inflammation as this may affect some of the former variables.

\section{Experimental methods}

Children were recruited from the Royal Children's Hospital, Brisbane, Australia, as part of a larger observational study. Their characteristics are outlined in Table 1. The study was conducted according to the guidelines laid down in the Declaration of Helsinki and all procedures involving human subjects/patients were approved by the Ethics Committees of the Royal Children's Hospital (2007/117), the University of Queensland (2006000409) and Cerebral Palsy League of Queensland (2008/2009 1021). Written informed consent was obtained from all subjects' parents or guardians. Exclusion criteria included coexistence of specific chronic diseases such as renal, cardiac or identified metabolic disorders, as well as gastric resection, which may otherwise confound results.

The parents of the children collected a three consecutive day dietary duplicate of all food consumed by their child. When the children were at school or in other care, instructions were given to return any unused portions of the food, so their intake sample could be adjusted accordingly. The food composite was then macerated and homogenised, then subsamples analysed for the direct quantity of protein. A sample of all fluids consumed was collected separately, along with their quantity, and calculated along with the food quantities, to give an accurate representation of consumption values.

For protein analysis, the food samples were digested in sulphuric acid with the added catalyst of copper sulphate. After digestion, the samples were analysed for $\mathrm{N}$ content using a Buchi Kjeldahl digestor unit (Buchi K438; Schweiz, Switzerland). The levels of $\mathrm{N}$ in the samples were used to calculate protein levels by using a converting factor of $6 \cdot 250^{(18)}$. Protein analyses were carried out with standard reference materials and the laboratory in-house reference materials for quality control and assurance. Energy intake was obtained from the same food samples via bomb calorimetry analysis.
Protein intakes of enterally fed children were calculated using food panel information provided by the relevant product companies, along with the volumes consumed per $\mathrm{d}$ by each child. All total values are reported as a percentage of minimum requirement for age and sex, as outlined by the National Health and Medical Research Council nutrient reference values for Australia and New Zealand ${ }^{(19)}$. For energy intakes, values are reported as a percentage of estimated average requirement for age and sex, also based on the above reference source.

Fasting blood samples were collected from participants first thing in the morning and lithium heparin plasma was available for albumin, urea, urate, creatinine and C-reactive protein assays. These were measured simultaneously on the Beckman Coulter Synchron Clinical System (Synchron LX; Clinical Systems, Brea, CA, USA), with the creatinine quantification via a modified Jaffé method ${ }^{(20)}$.

$Z$-scores were calculated for values which are known to vary with age and sex, such as height, weight, BMI, albumin, urate and creatinine. These were calculated from the Centers for Disease Control (2000) growth data (EPI INFO software; Centers for Disease Control, Atlanta, CA, USA) and previously published data $^{(21)}$, respectively. As both groups of children with $\mathrm{CP}$ were non-ambulatory, an estimated height was calculated based on a mean and predictions of stature from measurements of upper arm length, lower leg length and knee height ${ }^{(22)}$.

Statistical analyses were conducted using Microsoft Office Excel 2007 (Microsoft, Redmond, WA, USA), with comparison of means between CP and control children obtained via $t$ tests. $P$ values between orally and enterally fed children were calculated via a post hoc analysis. $P$ values below 0.05 were considered statistically significant. As no previous data exist in this area, a sample size of sixteen was selected, as it would detect a statistically significant difference if the means between the groups varied by 1 SD.

\section{Results}

Comparisons of group means are presented in Table 2.

Anthropometric, height and weight $z$-score correlations are presented in Table 3.

In the present cohort of orally fed children with $\mathrm{CP}$, anthropometric data demonstrate significantly reduced $z$-scores for

Table 1. Participant characteristics

(Mean values, standard deviations and $95 \%$ confidence intervals)

\begin{tabular}{|c|c|c|c|c|c|c|c|c|c|}
\hline & \multicolumn{6}{|c|}{ Cerebral palsy } & & & \\
\hline & \multicolumn{3}{|c|}{ Enterally fed } & \multicolumn{3}{|c|}{ Orally fed } & \multicolumn{3}{|c|}{ Controls } \\
\hline & Mean & SD & $95 \% \mathrm{Cl}$ & Mean & SD & $95 \% \mathrm{Cl}$ & Mean & SD & $95 \% \mathrm{Cl}$ \\
\hline Subjects $(n)$ & \multicolumn{3}{|c|}{9} & \multicolumn{3}{|c|}{15} & \multicolumn{3}{|c|}{24} \\
\hline Age (years) & $8 \cdot 1$ & $2 \cdot 9$ & $6 \cdot 2,10 \cdot 0$ & $7 \cdot 1$ & $2 \cdot 1$ & $6 \cdot 0,8 \cdot 2$ & $7 \cdot 3$ & $2 \cdot 0$ & $6 \cdot 5,8 \cdot 1$ \\
\hline \multicolumn{10}{|l|}{$\operatorname{Sex}(n)$} \\
\hline Male & & 7 & & \multicolumn{3}{|c|}{9} & \multicolumn{3}{|c|}{13} \\
\hline Female & \multicolumn{3}{|c|}{2} & \multicolumn{3}{|c|}{6} & \multicolumn{3}{|c|}{11} \\
\hline GMFCS IV & \multicolumn{3}{|c|}{2} & \multirow{2}{*}{\multicolumn{3}{|c|}{8}} & \multirow{2}{*}{\multicolumn{3}{|c|}{ NA }} \\
\hline GMFCS V & \multicolumn{3}{|c|}{7} & & & & & & \\
\hline
\end{tabular}

GMFCS, gross motor classification scale; NA, not applicable. 
weight (-1.92 (SD 1.59)), height (-1.68 (SD 1.0)) and BMI $\left(-1.06(\mathrm{sD} 1.62) \mathrm{kg} / \mathrm{m}^{2}\right)$ compared with the control group and are in agreement with previously published normative datasets. The enterally fed group, however, showed improved $z$-scores, compared with orally fed children, for weight $(-0.73$ (SD 1.24)) and BMI (0.52 (SD 1.01)), but not height $(-1.75$ (SD 0.90)). This was due to lower weight $z$-scores in the orally fed group, which also reached statistical significance when compared with the enterally fed group.

Calculation via the D'Agostino-Pearson Omnibut test for normality indicated no significant deviations from normal distribution within each of the three groups. However, when combining the groups of children with $\mathrm{CP}$, normality was not established for energy due to the large differences found between orally and enterally fed children's intakes.

Analysis via ANOVA revealed protein intakes to be significantly higher in the control group, compared with both orally and enterally fed children $(P=0 \cdot 005)$. Energy intakes were also significantly different between enterally and orally fed children $v$. controls $(P=0.006)$.

In relation to other biochemical variables, which may be indicative of protein metabolism, significant differences were found between children with $\mathrm{CP}$ and controls for urate $(P=0.002)$ and creatinine $(P<0 \cdot 001)$. Differences were also found between enterally $v$. orally fed children and controls for albumin $(P<0.001)$ and urea $(P=0.08)$ via ANOVA, although in the latter, significance between the means was reached for enterally fed children $v$. controls only $(P=0 \cdot 03)$. Inflammatory marker $\mathrm{C}$-reactive protein was also measured and found not to be increased in any of the groups. This latter component was included as an indicator of the acute-phase inflammatory response due to the potential of this phenomenon to decrease albumin levels irrespective of other parameters and hence potentially confound resulting data.

\section{Discussion}

The present anthropometric data support other previously published data ${ }^{(9-15)}$ and demonstrate differences in weight $z$-scores but not height $z$-scores when comparing enterally and orally fed children. The large standard deviation found in the CP group is affected by one of the orally fed children, with a weight $z$-score close to zero, having previously been administered enteral feeds which may have caused the unusually large weight $z$-score, compared with others in the orally fed group. Similarly, the enteral group contained a child who was partially enterally and orally fed, and as such had a much lower weight $z$-score than other children in this group. Height $z$-score standard deviation was closer to $1 \cdot 0$.

No significant correlations were found between weight $z$-score and either percentage of minimal requirement of protein or percentage of recommended daily energy intake in any of the groups. Interestingly, height was more closely related to protein intake in both control $(P=0.08)$ and enterally fed children $(P=0 \cdot 09)$, while height was also more closely correlated with energy intake in the enterally fed group $(P=0 \cdot 07)$. These measures may, however, reach significance with a larger sample size. 
Table 3. Anthropometric, height and weight $z$-score correlations

\begin{tabular}{|c|c|c|c|c|c|c|c|c|}
\hline \multirow[b]{3}{*}{ Correlation } & \multirow{2}{*}{\multicolumn{2}{|c|}{ Controls ( $n$ 24) }} & \multirow{2}{*}{\multicolumn{2}{|c|}{$\mathrm{CP}(n 24)$}} & \multicolumn{4}{|c|}{$\mathrm{CP}$} \\
\hline & & & & & \multicolumn{2}{|c|}{$\begin{array}{l}\text { Enterally fed } \\
\qquad(n 9)\end{array}$} & \multicolumn{2}{|c|}{ Orally fed $(n 15)$} \\
\hline & $r$ & $P$ & $r$ & $P$ & $r$ & $P$ & $r$ & $P$ \\
\hline Weight, $z$-score (\% minimum protein intake) & -0.11 & 0.70 & -0.01 & 0.97 & 0.52 & $0 \cdot 18$ & -0.06 & 0.87 \\
\hline Height, $z$-score ( $\%$ minimum protein intake) & 0.46 & 0.08 & 0.30 & 0.19 & 0.62 & 0.09 & 0.17 & 0.62 \\
\hline Weight, $z$-score (\% energy EAR) & -0.01 & 0.98 & -0.15 & 0.51 & 0.59 & 0.11 & 0.28 & 0.40 \\
\hline Height, $z$-score ( $\%$ energy EAR) & -0.28 & 0.31 & -0.29 & 0.21 & 0.67 & 0.07 & 0.34 & 0.31 \\
\hline
\end{tabular}

$\mathrm{CP}$, cerebral palsy; EAR, estimated average requirement.

Compared with a reference population of age- and sex-matched typically developing children, a study of forty children with marked CP documented lower energy expenditure and high body fat content in children particularly if they were enterally fed ${ }^{(23)}$. The authors have also highlighted the potential risk of overfeeding with available enteral feeds due to a potential shift from negative to positive energy balance that enhances this fat accumulation. A longitudinal study had similar findings which showed that children with severe motor impairment gained more fat than muscle over time and supported the theory that weight gain in these children may be mainly comprised of fat gain ${ }^{(24)}$. A number of other smaller studies have also shown an increase in fat accumulation after gastrostomy insertion ${ }^{(10,12,16)}$. This may explain the typical increases in weight but not height $z$-scores.

Significantly reduced body protein levels for age and height have been previously noted in fifty-nine children with marked CP using $\gamma$-neutron activation analysis ${ }^{(25)}$. The advantage of this method is that it is a direct measure of body $\mathrm{N}$ and is not affected by other factors such as hydration status ${ }^{(26)}$. Frequently utilised body composition assessment which uses measures of total body water with assumed hydration factors to equate lean tissue mass may suffer from bias due to an abnormal hydration $^{(27)}$. Hyperhydration has been reported in children with malnutrition ${ }^{(28)}$. This has been attributed to a decrease of plasma proteins, mainly in the form of albumin, which act to maintain oncotic pressure within the blood vessels and hence assist with the resorption of fluid from interstitial spaces ${ }^{(29)}$. Subsequent increases under these circumstances may increase total body water, falsely elevate lean body mass and hence total body protein estimations, when calculated via methods which utilise assumed hydration factors ${ }^{(25)}$. A variety of studies have found mixed results in the calculation of total body water $^{(30-32)}$, which may be the result of confounding malnutrition. Each of these studies also had children with varying severities of $\mathrm{CP}$, which is likely to have affected the levels of confounding from potential malnutrition issues. Assumption relating to the hydration of the fat-free mass in a number of children with CP may not be valid, and this could affect the ability to accurately predict their lean mass and hence total body protein, from such measures.

Bone health in these children is also a concern as there is a tendency for spontaneous fractures as a result of osteopaenia $^{(33)}$, which has been attributed to nutritional ${ }^{(34)}$ and non-nutritional $^{(35)}$ factors. Protein plays an important role in
Ca homeostasis as it affects both its intestinal absorption ${ }^{(36)}$ and retention in the body ${ }^{(37)}$. A recent well-designed study by Arrowsmith et $a l^{(38)}$ demonstrated no significant increases in total body protein percentage for age or bone mineral content for age or height, after enteral feeding for a median of 19.4 months. When these parameters were compared with height-matched, as opposed to age-matched, controls, significant increases were found with increases from 83 to $99 \%{ }^{(38)}$.

Although all of the groups in the present study were consuming protein within current recommendations, recent evidence has suggested that these recommendations may actually be underestimating human protein requirements by approximately $40-50 \%{ }^{(39)}$. In the past, $\mathrm{N}$ balance studies were utilised which have been documented to suffer from errors. These are believed to have occurred via an overestimation of $\mathrm{N}$ intake, coupled with an underestimation of $\mathrm{N}$ excretion, which in all lead to a shortfall in inference of the actual protein requirements ${ }^{(40)}$. The new method which is fast becoming accepted determines amino acid requirements via an indicator amino acid oxidation method which involves feeding a range of test intakes and measuring the response in oxidation. Here, the increasing intake of the limiting amino acid will linearly decrease the oxidation of this particle until no further change is detected. This point indicates when requirement has been reached with the entire process reflecting the amino acids increased incorporation into protein ${ }^{(41)}$. From these later studies, values for some of the essential amino acids such as leucine, lysine, threonine and valine appear to be up to two times higher than originally thought ${ }^{(42)}$. The National Health and Medical Research Council's current recommendations for children based on a population's estimated average requirement and an individual's recommended daily intake safe requirements are of 0.78 and $0.94 \mathrm{~g} / \mathrm{kg}$ per $\mathrm{d}$ for boys and 0.61 and $0.87 \mathrm{~g} / \mathrm{kg}$ per $\mathrm{d}$ for girls, respectively. As determined by the indicator amino acid oxidation, new requirements are suggested to be 1.35 and $1.6 \mathrm{~g} / \mathrm{kg}$ per $\mathrm{d}$, which demonstrate the extreme inadequacy of current recommendations ${ }^{(43)}$.

If these newer estimations were used in the present study group to ascertain the percentage of minimum protein requirements, orally fed children would on average be consuming 140 (SD 60)\%, enterally fed children 119 (SD 32) \% and control children 208 (SD 80) \%.

Creatinine is often utilised as a surrogate measure for muscle mass ${ }^{(44)}$, and as such may be an indicator of total body protein 
status. In the present $\mathrm{CP}$ groups, creatinine was found to be significantly lower than in control children. This may also be explained in part due to notable inactivity, which has been shown to increase protein catabolism and therefore downregulate protein synthesis ${ }^{(45)}$. Recent studies have shown that increasing protein intakes by $15-16.5 \mathrm{~g}$ of essential amino acids may reduce inactivity-related loss of skeletal and myocardial muscles in both young ${ }^{(46)}$ and old ${ }^{(47)}$ subjects. The quality of the protein has also been demonstrated to affect protein synthesis during inactivity ${ }^{(48)}$. In typically developing adolescents, protein intakes greater than recommended have also been associated with positive health indicators such as waist circumference, insulin resistance and TAG levels ${ }^{(49)}$.

Albumin is the most abundant protein in human plasma and represents $40-60 \%$ of total protein. As plasma levels depend on protein intake, albumin is often used as a surrogate to assess nutritional status ${ }^{(50)}$. Hypoalbuminaemia is associated with impaired protein metabolism, infection or stress, impaired hepatic function or toxic damage ${ }^{(17)}$. The present data show significantly decreased levels of albumin in our enterally fed group compared with the other two groups. Urea is also found to be reduced in our enterally fed group. A low-protein diet and starvation cause a decrease in the synthesis of urea ${ }^{(51)}$ as particular amino acids are favoured for recycling, a process which aids in decreasing further protein catabolism ${ }^{(52)}$. A low reading of urea may be indicative of inadequate protein intake, although it may also occur in severe liver disease ${ }^{(53)}$

Urate is a nitrogenous compound that is a catabolism product of the DNA building block purine ${ }^{(51)}$ and as such may give an indication of the state of protein nutriture. A low level of urate has been identified in Alzheimer's disease and associated with increased progression of cognitive decline. This is thought to be due to its function as one of the major antioxidants in plasma ${ }^{(54)}$. The children with $\mathrm{CP}$ in the present study had significantly reduced levels of plasma urate, as well as many with high-level cognitive impairment, when compared with their typically developing counterparts.

Limitations to the present study include the relatively small number of participants due to its nature as a pilot study. However, significant differences between the groups were documented and should be reason to further investigate the disparities, given the presented literature. Future studies in larger samples should focus on methods which directly determine total body protein and compare with different levels, quality and composition of intakes, particularly in children with eating disorders and also those solely reliant on artificial nutrition.

\section{Conclusion}

Children with CP are well documented to have issues with malnutrition, growth and development. Given the importance of protein in all aspects of physiology and growth, adequacy of current recommendations warrants further investigation, particularly in those who are permanently administered standardised enteral formulas which adhere to these potentially inadequate guidelines.

The intricate workings of body biochemistry and the need for this to be adequately balanced call for nutrition focus in these children to be expanded beyond the commonly held isolated theories of energy intake and expenditure affecting growth and development.

\section{Acknowledgements}

N. S. is supported by a Royal Children's Hospital Foundation PhD scholarship and the University of Queensland. R. B. is supported by the National Health and Medical Research Council Career Development award, Smart State Fellowship and the University of Queensland. P. S. W. D., L. V. and N. S. are supported by the School of Medicine, the University of Queensland. U. T. is supported by Queensland Health, Centre for Public Health Sciences. N. S. was the project coordinator and the main author of this manuscript. N. S. provided research assistance for the project. U. T., Pam Kahlon and Hans Yates performed the laboratory analyses. P. S. W. D., L. V. and R. B. supervised the project and revised the manuscript. There are no conflicts of interest to declare.

\section{References}

1. Soylu OB, Unalp A, Uran N, et al. (2008) Effect of nutritional support in children with spastic quadriplegia. Pediatr Neurol 39, 330-334.

2. Rogers B (2004) Feeding method and health outcomes of children with cerebral palsy. J Pediatr 145, S28-S32.

3. Sullivan PB, Lambert B, Rose M, et al. (2000) Prevalence and severity of feeding and nutritional problems in children with neurological impairment: Oxford Feeding Study. Dev Med Child Neurol 42, 674-680.

4. Samson-Fang LJ \& Stevenson RD (1998) Linear growth velocity in children with cerebral palsy. Dev Med Child Neurol 40, 689-692.

5. Samson-Fang L, Fung E, Stallings VA, et al. (2002) Relationship of nutritional status to health and societal participation in children with cerebral palsy. J Pediatr 141, 637-643.

6. Henderson RC, Kairalla B, Abbas A, et al. (2004) Predicting low bone density in children and young adults with quadriplegic cerebral palsy. Dev Med Child Neurol 46, 416-419.

7. Henderson RC, Kairalla JA, Barrington JW, et al. (2005) Longitudinal changes in bone density in children and adolescents with moderate to severe cerebral palsy. J Pediatr 146, $769-775$.

8. Escott-Stump S (2008) Enteral nutrition. In Nutrition and Diagnostics - Related Care, 6th ed. [D Troy, editor]. Philadelphia, PA: Lippincott Williams \& Wilkins.

9. Shapiro BK, Green P, Krick J, et al. (1986) Growth of severely impaire children: neurological versus nutritional factors. Dev Med Child Neurol 28, 729-733.

10. Sanders K, Cox K, Cannon R, et al. (1990) Growth response to enteral feeding by children with cerebral palsy. JPEN 14, $23-26$

11. Lewis D, Khoshoo V, Pencharz PB, et al. (1994) Impact of nutritional rehabilitation on gastroesophageal reflux in neurologically impaired children. J Pediatr Surg 29, 167-170.

12. Isaacs J, Georgeson KE, Cloud HH, et al. (1994) Weight gain and triceps skinfolds fat mass after gastrostomy placement in children with developmental disabilities. J Am Diet Assoc 94, 849-854.

13. Brant CQ, Stanich P \& Ferrari JAP (1999) Improvement of children's nutritional status after enteral feeding by PEG: an interim report. Gastrointest Endosc 50, 183-188. 
14. Sullivan PB (2002) A 12-month prospective study of gastrostomy feeding in disabled children. Arch Dis Child 86, A22.

15. Sullivan PB, Juszczak E, Bachlet AME, et al. (2005) Gastrostomy tube feeding in children with cerebral palsy: a prospective, longitudinal study. Child Care Health Dev 31, 491-492.

16. Rempel GR, Colwell SO \& Nelson RP (1988) Growth in children with cerebral palsy fed via gastrostomy. Pediatrics 82, 857-862.

17. Jackson AA (2003) Severe malnutrition. In Oxford Textbook of Medicine, 4th ed. [DA Warrell, TM Cox and JD Firth, editors]. New York, NY: Oxford University Press.

18. Thompson M, Owen L, Wilkinson K, et al. (2002) A comparison of the Kjeldahl and Dumas methods for the determination of protein in foods, using data from a proficiency testing scheme. Analyst 127, 1666-1668.

19. Australian-Government (2005) Nutrient and Reference Values for Australia and New Zealand: Including Recommended Dietary Intakes. Canberra: Department of Health and Ageing.

20. Junge W, Wilke B, Halabi A, et al. (2004) Determination of reference intervals for serum creatinine, creatinine excretion and creatinine clearance with an enzymatic and a modified Jaffé method. Clin Chim Acta 344, 137-148.

21. Soldin SJ, Brugnara C \& Wong EC (2007) Pediatric Reference Intervals. Washington, DC: AACC Press.

22. Spender Q, Cronk C, Charney E, et al. (1989) Assessment of linear growth of children with cerebral palsy: use of alternative measures to height or length. Dev Med Child Neurol 31, 206-214.

23. Sullivan PB, Alder N, Bachlet AM, et al. (2006) Gastrostomy feeding in cerebral palsy: too much of a good thing? Dev Med Child Neurol 48, 877-882.

24. Ohata K, Tsuboyama T, Haruta T, et al. (2009) Longitudinal change in muscle and fat thickness in children and adolescents with cerebral palsy. Dev Med Child Neurol 51, 943-948.

25. Arrowsmith FE, Allen JR, Gaskin KJ, et al. (2006) Reduced body protein in children with spastic quadriplegic cerebral palsy. Am J Clin Nutr 83, 613-618.

26. Baur LA, Allen BJ, Rose A, et al. (1991) A total body nitrogen facility for paediatric use. Phys Med Biol 36, 1363-1375.

27. Roubenoff R, Kehayias J, Dawson-Hughes B, et al. (1993) Use of dual-energy X-ray absorptiometry in body-composition studies: not yet a 'gold standard'. Am J Clin Nutr 58, 589-591.

28. Shetty PS (1995) Body composition in malnutrition. In Body Composition Techniques in Health and Disease, pp. 71-84 [PSW Davies and TJ Cole, editors]. Cambridge: Cambridge University Press.

29. Mergner WJ \& Trump BF (1995) Hemodynamic disorders. In Essential Pathology, 3rd ed. [E Rubin, editor]. Philadelphia, PA: Lippincott Williams \& Wilkins.

30. Bandini LG, Schoeller DA, Fukagawa NK, et al. (1991) Body composition and energy expenditure in adolescents with cerebral palsy or myelodysplasia. Pediatr Res 29, 70-77.

31. van den Berg-Emons R, van Baak M \& Westerterp KR (1998) Are skinfold measurements suitable to compare body fat between children with spastic cerebral palsy and healthy controls? Dev Med Child Neurol 40, 335-339.

32. Berg K \& Isaksson B (1970) Body composition and nutrition of school children with cerebral palsy. Acta Paediatr Scand Suppl 204, 41-52.

33. Leet AI, Mesfin A, Pichard C, et al. (2006) Fractures in children with cerebral palsy. J Pediatr Orthop 26, 624-627.

34. Henderson RC, Lin PP \& Greene WB (1995) Bone-mineral density in children and adolescents who have spastic cerebral palsy. J Bone Joint Surg Am 77, 1671-1681.

35. Henderson RC, Lark RK, Gurka MJ, et al. (2002) Bone density and metabolism in children and adolescents with moderate to severe cerebral palsy. Pediatrics 110, e5.
36. Kerstetter JE, O'Brien KO \& Insogna KL (1998) Dietary protein affects intestinal calcium absorption. Am J Clin Nutr $\mathbf{6 8}$, $859-865$.

37. Hunt JR, Johnson LK \& Fariba Roughead ZK (2009) Dietary protein and calcium interact to influence calcium retention: a controlled feeding study. Am J Clin Nutr 89, 1357-1365.

38. Arrowsmith F, Allen J, Gaskin K, et al. (2010) The effect of gastrostomy tube feeding on body protein and bone mineralization in children with quadriplegic cerebral palsy. Dev Med Child Neurol 52, 1043-1047.

39. Elango R, Humayun MA, Ball RO, et al. (2010) Evidence that protein requirements have been significantly underestimated. Curr Opin Clin Nutr Metab Care 13, 52-57.

40. Institute of Medicine (2005) Dietary Reference Intakes: Energy, Carbohydrate, Fiber, Fat, Fatty acids, Cholesterol, Protein and Amino Acids [FaN Board, editor]. Washington, DC: National Academy Press.

41. Elango R, Ball RO \& Pencharz PB (2008) Individual amino acid requirements in humans: an update. Curr Opin Clin Nutr Metab Care 11, 34-39.

42. Elango R, Ball R \& Pencharz P (2009) Amino acid requirements in humans: with a special emphasis on the metabolic availability of amino acids. Amino Acids 37, 19-27.

43. Elango R, Humayun MA, Ball RO, et al. (2009) Evidence that protein requirements in healthy school-age children are significantly underestimated in current recommentations. FASEB J 23, 227.8.

44. Gibson RS (2005) Assessment of Protein Status. Principles of Nutritional Assessment, 2nd ed., pp. 403-442. New York, NY: Oxford University Press.

45. Guadagni M \& Biolo G (2009) Effects of inflammation and/or inactivity on the need for dietary protein. Curr Opin Clin Nutr Metab Care 12, 617-622.

46. Paddon-Jones D, Sheffield-Moore M \& Urban RJ (2004) Essential amino acid and carbohydrate supplementation ameliorates muscle protein loss in humans during 28 days bedrest. J Clin Endocrinol Metab 89, 4351-4358.

47. Ferrando AA, Paddon-Jones D, Hays NP, et al. (2010) EAA supplementation to increase nitrogen intake improves muscle function during bed rest in the elderly. Clin Nutr 29, 18-23.

48. Antonione R, Caliandro E, Zorat F, et al. (2008) Whey protein ingestion enhances postprandial anabolism during shortterm bed rest in young men. J Nutr 138, 2212-2216.

49. Adamson KA, Daratha KB \& Bindler RC (2010) Dietary quality and relationships with health indicators among early adolescents. ICAN 2, 158-164.

50. Burtis C \& Ashwood E (1994) Amino Acids and Proteins Tietz Textbook of Clinical Chemistry, pp. 701. Philadelphia, PA: W.B. Saunders Company.

51. Pagana K \& Pagana T (2007) Mosby's Diagnostic and Laboratory Test Reference [B Dennison, editor]. St Louis, MO: Mosby Elsevier.

52. Torun B (2006) Protein-energy malnutrition in paediatric and adolescent disorders. In Modern Nutrition in Health and Disease, 10th ed., pp. 881-908 [M Shils, M Shik, AC Ross, B Caballero and RJ Cousins, editors]. Philadelphia, PA: Lippincott Williams \& Wilkins.

53. Heimburger D (2006) Adulthood. In Modern Nutrition in Health and Disease, 10th ed. [M Shils, M Shike, AC Ross, B Caballero and RJ Cousins, editors]. Philadelphia, PA: Lippincott Williams \& Wilkins.

54. Irizarry MC, Raman R, Schwarzschild MA, et al. (2009) Plasma urate and progression of mild cognitive impairment. Neurodegener Dis 6, 23-28. 